\title{
Sentimentalism and the Intersubjectivity \\ of Aesthetic Evaluations
}

Fabian Dorsch ${ }^{\dagger}$

\begin{abstract}
Within the debate about the epistemology of aesthetic appreciation, it has a long tradition, and is still very common, to endorse the sentimentalist view that our aesthetic evaluations are rationally grounded on, or even constituted by, certain of our emotional responses to the objects concerned. Such a view faces, however, the serious challenge to satisfactorily deal with the seeming possibility of faultless disagreement among emotionally based and epistemically appropriate verdicts. I will argue that the sentimentalist approach to aesthetic epistemology cannot accept and accommodate this possibility without thereby undermining the assumed capacity of emotions to justify corresponding aesthetic evaluations - that is, without undermining the very sentimentalist idea at the core of its account. And I will also try to show that sentimentalists can hope to deny the possibility of faultless disagreement only by giving up the further view that aesthetic assessments are intersubjective - a view which is almost as traditional and widely held in aesthetics as sentimentalism, and which is indeed often enough combined with the latter. My ultimate conclusion is therefore that this popular combination of views should better be avoided: either sentimentalism or intersubjectivism has to make way.
\end{abstract}

\section{Introduction}

1. Emotions can possibly stand in two kinds of rational relations: they can be supported by reasons, such as judgements or facts concerned with the non-evaluative nature of objects; and they can themselves provide reasons, for instance for belief or action. My main concern in this essay is with a certain aspect of the latter, namely the capacity (or lack thereof) of emotions or sentiments to epistemically justify aesthetic evaluations, that is, ascriptions of aesthetic values to objects. That is, I will be concerned with epistemological issues concerning the idea of emotion-based aesthetic evaluations. Only in passing will I say also something about the rational underpinning of our emotional responses themselves.

The view that certain of our emotional responses indeed possess the capacity to justify aesthetic evaluations, and that our aesthetic assessments are primarily, if not always, epistemically based on or constituted by these responses, has become almost orthodoxy in aesthetics, or at least the predominant approach to the epistemology of aesthetic evaluations. ${ }^{1}$ Moreover, this view is very often combined with the further

$†$ Department of Philosophy, University of Fribourg, Miséricorde, Avenue de l'Europe 20, CH-1700 Fribourg, Switzerland; Email: fabian.dorsch@uclmail.net

1 Cf., for instance, the sentimentalist theories put forward in Hume 1998, Kant 1990, sections 1ff., Budd 1995, 11ff. and 38f., Goldman 1995, 22, and the semi-sentimentalist view proposed in Levinson 1995. One notable exception is Bender 1995 who construes aesthetic evaluations instead as inferentially based. As it has been suggested to me by an 
view that all our aesthetic evaluations are intersubjective, in the rough sense that at least neither their truth-values, nor the exemplifications of the ascribed values are relativised to specific human subjects or groups. ${ }^{2}$ I will label the first of these two views about aesthetic evaluations sentimentalism, and the second intersubjectivism. ${ }^{3}$

Contrary to the still strong and influential tendency in aesthetics to combine sentimentalism and intersubjectivism, I aim to show that the two views should not be endorsed simultaneously. That is, in my view, sentimentalism should be upheld only if intersubjectivism is rejected; and intersubjectivism should be upheld only if sentimentalism is rejected. Given that I furthermore take the denial of intersubjectivism to be highly implausible (although I do not intend to argue for this here $^{4}$ ), I believe that, ultimately, it is sentimentalism concerning aesthetic evaluations which should give way. ${ }^{5}$

Here is how I will proceed. First of all, I will spell out the main elements of the sentimentalist and the intersubjectivist approaches to aesthetic appreciation (cf. sections 2-7). Then, I will formulate a challenge to this approach, which arises out of what is usually described as the seeming possibility of faultless disagreement among our emotional responses and the related aesthetic evaluations (cf. section 8). After this, I will discuss and reject the various strategies which a sentimentalist may adopt in order to be able to accept and accommodate this possibility (cf. sections 9-17). And

anonymous referee, adopting a sentimentalist outlook may perhaps be plausible only with respect to certain kinds of aesthetic value (e.g., concerning the funny, or the disgusting). If so, my discussion may have to be similarly restricted in its scope (and my notion of an 'overall aesthetic merit' of a work to be understood as denoting the most comprehensive and non-descriptive aesthetic value said to be accessible by means of emotions).

2 Cf. Hume 1998, Kant 1990, McDowell 1983, Budd 1995, ch. 1, and 1999, and presumably Levinson, who believes that "pleasure that testifies to artistic value must go beyond a single encounter, must be experiencable by others, and at other times" (Levinson 1995, 13; cf. also 16).

3 Of course, both notions may be understood in many other ways. In particular, a wider notion of sentimentalism may be used to characterize the dependence of our evaluations or evaluative concepts on our emotional capacities in more general terms (cf. D'Arms \& Jacobson 2003, 127f.); while a narrower notion may be limited to the view that aesthetic judgements are about or express sentiments, rather than facts, and are not (genuinely) cognitive or truth-apt (cf. Zangwill 2001, 149ff.). By contrast, my notion focusses on the epistemic link between emotions and evaluations (i.e., on the idea that the former can justify the latter by either grounding or constituting them) and is meant to include also positions which take aesthetic judgements to be truth-apt despite their being epistemically based on emotional responses.

4 Cf. e.g., Hume 1998, Kant 1990 and Wollheim 1980 for powerful criticisms of more subjectivist approaches to aesthetic epistemology.

5 Despite my exclusive focus on the aesthetic case, I hope that the following considerations on the possible epistemic relationship between emotions and evaluations do not depend on idiosyncrasies of the aesthetic debate or its subject matter and are therefore also applicable to other kinds of value. In particular, I hope that the arguments presented here put pressure on the views of the few moral epistemologists - Wiggins 1987b and Döring 2007 prominently among them - who take emotions or sentiments to be justifying grounds or constituents of evaluations. 
finally, I will try to undermine any plausible sentimentalist attempt to deny it (cf. sections 18-20). As a result, I will conclude that sentimentalism is forced to give up intersubjectivism.

\section{Sentimentalism}

2. Sentimentalism, as understood here, is the epistemological view that certain of our sentiments or emotional responses can - and, indeed, often do - justify our aesthetic evaluations. The underlying idea is that our aesthetic assessments are typically based on, or constituted by, the relevant emotions, and that the appropriateness of the latter transfers to the former. This implies that there are strict correspondances between (sets of) emotional responses and aesthetic values (or ascriptions thereof), which means at least that each kind of aesthetic value is uniquely linked to a certain type of emotional response. For instance, the particular aesthetic merit of being exciting may be said to correspond to feelings of excitement; or, more generally, the value of being aesthetically good to feelings of pleasure. But it may also mean that differences in degree among the values parallel differences in intensity among the emotional responses. Sentimentalism is compatible with a wide variety of more concrete views about the nature of aesthetic appreciation. For instance, sentimentalist may take aesthetic evaluations to consist in, or to express, emotional responses. ${ }^{6}$ But they may equally take them to be based on emotions in a similar way, in which perceptual judgements are based on perceptions, or introspective judgements on the respective first-order states. ${ }^{7}$

3. Among the main motivations for sentimentalism is the observation that our respective emotional responses are rationally sensitive to evidence for aesthetic (or other kinds of) worth. When we try to explain why we value certain artworks, or try to convince someone else of our appraisal, we usually point to certain non-evaluative facts about the object - for instance, how it looks or sounds, which story it tells, and how, who created it, and when, and so on (cf. Goldman 1995, 12ff., and Zangwill

6 Examples are Goldman 1995, e.g., 22, and the aesthetic theories - such as those discussed by Hopkins 2001 and Todd 2004 - which are in the spirit of Blackburn's or Gibbard's versions of moral expressivism. The account put forward by Hume 1998, and perhaps also that of Kant 1990, appear to involve similar ideas.

7 The theory defended by McDowell 1983 and 1985, as well as aesthetic positions in the wake of the moral accounts of Wiggins 1987b and Wright 1988, are of this kind. Note that also Kant stresses that aesthetic judgements are primarily about the subject's own emotions, and only then about the experienced objects (Kant 1990, 3f.). 
2001, 20ff. and 37ff.). But these and similar facts are also among those which are relevant for the occurrence and nature of our emotional responses. When we hear that the painting, which we took to be rather original for the Romantic period in its dispassionate objectiveness stems in fact from the late Nineteenth Century, our excitement about it will wane. And our admiration for a piece of music may well be heightened by the recognition of its intricate and original structure. The impact of the respective non-evaluative facts on our emotional responses is thereby evidently rational in nature. For both the occurrence and the adequacy of our emotions is at least partly a matter of the contents of our mental representations of these facts (cf. Goldie 2004). For example, feeling awed when confronted with a certain poem, despite taking it to be unoriginal, bland, uninteresting in its content and stylistically flawed in many ways, would not be the right kind of emotional response to that piece of writing, at least not within the context of an aesthetic experience of the poem. This provides support for the sentimentalist view that emotions mediate rationally between our non-evaluative experiences of objects and our aesthetic evaluations of them. For it can elucidate why and how our assessments are responsive to and based on relevant reasons, that is, on relevant non-evaluative facts about the objects to be evaluated. ${ }^{8}$

\section{The idea of reflection}

4. Sentimentalism is often combined with two other ideas: that (some of) our

8 Other important motivations for sentimentalism are: (i): the particularist insight that aesthetic assessment is typically not the matter of deductive inference on the basis of judgements about non-aesthetic features (cf. Kant 1985, section 56, Sibley 1965, Budd 1999, Goldman 1995, 132ff., and Bender 1995); (ii) the fact that sentimentalism promises to explain certain aspects of the central role and importance of emotions in aesthetic evaluation, such as the intimate link between aesthetic values and emotional terms (e.g., 'exciting', 'wonderful', 'stimulating', 'awesome', 'moving', 'disgusting', 'appalling' or 'outrageous'; cf. Williams 1965, 218f., and McNaughton 1988, 8), or the function of the emotional responses to draw our attention to reasons for aesthetic assessment; and (iii) perhaps also the seeming subjectivity of our aesthetic assessments.

However, none of these points compel one to accept sentimentalism. Although they may provide considerable support for this approach to aesthetic appreciation, there is still room for alternative theories fitting or explaining the noted facts as well as sentimentalism. In particular, a more rationalist view can hope to be on equal standing with sentimentalism with respect to the considerations commonly put forward in favour of the latter. According to such a view, aesthetic assessment is a matter of true or false judgements about the aesthetic merit of objects, made on the basis of inductive considerations and inferences to the best explanation concerning the non-aesthetic features of those objects (cf. Bender 1995). And it can assign to emotional responses the role of merely drawing our attention to (already independently recognized) reasons for aesthetic assessment, rather than that of grounding or constituting such evaluations. 
aesthetic evaluations (as well as any corresponding emotional responses) have the capacity to reflect the aesthetic worth of objects; and that our aesthetic evaluations are either appropriate or inappropriate, and possibly in more than one way.

An evaluation reflects a certain value of an object just in case the object exemplifies the value which the evaluation ascribes to him. Perhaps all our aesthetic evaluations reflect actual instances of aesthetic value; or perhaps only those which are appropriate or fitting (as I will say). The idea of reflection is not very strong and should be uncontroversial. It is rather weak because the notion of having a value which it invokes is used in such a way as not to entail any strong metaphysical or other commitments, apart from the presupposition that talking of the values of objects is legitimate in some sense or another. Indeed, it should be compatible even with eliminativist positions or error theories which deny that there actually are any exemplifications of aesthetic values, but which nonetheless accept that it makes sense to speak of the aesthetic worth of objects and provide a satisfactory theory of such talk. Furthermore, the idea of reflection is rather weak also because the notions of reflecting and, if applicable, of fitting evaluations may likewise be understood in a very non-committal way. While it may be proposed that aesthetic responses reflect instances of aesthetic worth by cognizing them, it may also be proposed that they reflect exemplifications of aesthetic values simply by projecting them onto their bearers. All that the idea of reflection presupposes is that objects have values, and that there is some kind of correspondance between these values and those evaluations (and, perhaps, those emotional responses) which ascribe or assign them again perhaps in a rather loose sense which does not require, say, the involvement of respective concepts - to the objects. It is therefore not very demanding or costly to endorse the idea of reflection. On the contrary, it would seem to be highly implausible to reject it, given that this would mean having to to stop talking of objects as bearers of values, and of evaluations as representing and potentially reflecting these values.

\section{Epistemic appropriateness and fittingness}

5. According to the idea of appropriateness, on the other hand, some evaluations are better than others; and the former are to be preferred over the latter - say, in respect to the issue of which we should endorse. For example, the claim that Hamlet is a masterpiece is said to be more adequate than the claim that it is a mediocre play. And we should thus hold on to the former and give up the latter. Evaluations may be taken 
to be better or worse than others in basically two ways: in relation to their epistemic standing, that is, their justification; and in relation to their reflecting the values of their objects. To return to the example, the first claim about Hamlet may be better than the second because it has been made in the right way, or because it reflects better the actual worth of the play. To distinguish the two senses in which evaluations may differ in appropriateness, I will differentiate between the epistemic appropriateness and the fittingness of assessments.

The idea of an epistemic appropriateness of aesthetic evaluations expresses the view that such assessments are either justified or unjustified, namely in the light of the relevant reasons available to us and, in particular, with respect to the aim of getting access to the aesthetic values of objects. The idea is often linked to the postulation of suitable conditions which suffice to ensure such an adequacy in appreciation (cf. Hume 1998, Levinson 1995, 15ff., and Goldman 1995, 21f.; cf. also, more generally, Wright 1988 and 1992). Which conditions are suitable in this respect may perhaps differ from case to case, depending on, say, the particular subjects, objects or aesthetic values concerned. But the conditions will surely put certain demands on the evaluating subjects, and perhaps also on the environmental circumstances. Accordingly, it is often required that subjects are fully and correctly aware of all the relevant features or acts concerning the object to be evaluated, which again presupposes that they are sufficiently attentive, sensitive and experienced in these matters; and that their further consideration of these features or facts happens in a rational and impartial way, and with no cognitive fault involved (cf. Hume 1998, Kant 1990, sections 2ff., Goldman 1995, 21f., and Zangwill 2001, 152ff.). And the satisfaction of such conditions may furthermore require, say, that the right kinds of interaction with the object are possible or permitted, or that the right kinds of observational conditions obtain. In the context of sentimentalism, any assumed epistemic justification of evaluations will be a matter of the standing of the relevant emotional responses and of their relationship to the assessments. Hence, if the emotional responses occur under suitable conditions, they acquire the power to justify corresponding evaluations; and if they then indeed lead to such assessments, they actually render them justified.

The idea of fittingness, on the other hand, becomes relevant for the identification of those evaluations which actually reflect the aesthetic worth of objects. Assuming that there is this form of appropriateness in aesthetic evaluation amounts to maintaining that not all assessments are equal in their reflection of aesthetic merit, and that, 
more precisely, only fitting evaluations correspond to instances of aesthetic values. ${ }^{9}$ Fittingness may then be spelled out in terms of truth; but it may also be spelled out in terms of some other kind of appropriateness, such as some form of emotional adequacy which does not amount to truth, while perhaps being very similar to truth. ${ }^{10}$

6. Proponents of sentimentalism, who accept that our aesthetic evaluations can be appropriate or inappropriate in one or more ways, may differ on how they conceive of the relevant kinds of appropriateness (i.e., epistemic appropriateness and fittingness), as well as their relationship. But there is much agreement on the idea that epistemic appropriateness is either conducive to or constitutive of fittingness.

Many theories accept the truth-aptness of evaluations and, correspondingly, understand fittingness in terms of truth. And although they may differ in their interpretation of the nature of the truth involved and of its link to epistemic appropriateness, they all assume that the latter is likely to, or even does, ensure the former. ${ }^{11}$ Indeed, it would be highly implausible to endorse an epistemological theory which takes truth and epistemic appropriateness to be more independent of each other. On such a view, the acquisition of true - rather than false - evaluations would be an arbitrary matter beyond our control. Given that striving for justified assessments would not be more likely to guarantee truth than striving for unjustified assessments, the respective criteria for epistemic appropriateness (e.g., full information, unbiasedness, attentiveness, etc.) could not guide us any more in the aim to discover the true aesthetic values of objects. And the resulting cognitive irrelevance of these criteria would raise the question of why we should care at all about epistemic appropriateness and about the related justificatory potential of our respective emotional responses.

However, there are also theories which deny the truth-aptness of aesthetic verdicts

9 D'Arms and Jacobson 2000 make a very similar use of the notion of fittingness with respect to emotions and their accurate presentation of some of their target's evaluative features.

10 Cf. the discussions in de Sousa 2002 and 2007, and in Morton 2002; and cf. also the notion of appropriate expressions in Gibbard 1990).

11 Some accounts of this kind assume that evaluations are (substantially) true when and because they successfully track instances of values which are there, as genuine parts of the world, to be recognized by us (cf. McDowell 1983 and 1985, and Wiggins 1987b). Other accounts take evaluations to be (presumably less substantially) true when and because they determine, rather than recognize, which objects have which values (cf. Wright 1988 and Goldman 1995). The idea is that it is our epistemically best opinions which reflect the aesthetic worth of objects and, hence, should count as true (cf. Wright 1988 and 1992). Besides, both kinds of view may vary in whether they take our epistemically appropriate evaluations to partly constitute the aesthetic values of the objects in question, or merely to pick them - or the respective underlying features of the objects constituting them - out (cf. McFarland \& Miller 1998 for the difference). McDowell, Wiggins and perhaps also Wright seem to favour the constitutionist alternative, while Goldman may be read as opting for the more reductionist view. 
and instead assume only a single kind of aesthetic appropriateness - for instance, the emotional adequacy mentioned above - which fulfils the role of both epistemic appropriateness and fittingness by ensuring single-handedly that the resulting assessments count as justified and as reflecting the aesthetic worth of the objects concerned. $^{12}$ For such theories, epistemic appropriateness simply amounts to fittingness. Hence, combining sentimentalism with the idea of appropriateness should involve the affirmation of the claim that epistemic appropriateness is conducive to or constitutive of fittingness.

\section{Intersubjectivism}

7. As already noted, it is very common in aesthetics to combine sentimentalism with intersubjectivism. As I understand intersubjectivism, it implies at least two important ideas (although it may not simply reduce to them). First, it entails that whether an object in fact exemplifies a particular aesthetic value or not is not relativised to certain subjects or groups of subjects among humanity, but equal for all actual or possible human beings. This means that objects are beautiful or disgusting for all humans (or none), but not, say, beautiful-for-me and disgusting-for-you. And second, intersubjectivism entails that whether aesthetic assessments reflect the aesthetic merit of an object or not is not relativised to certain subjects or groups of subjects among humanity, but equal for all actual or possible human beings. This means - for instance, if reflection and fittingness are spelled out in terms of truth - that aesthetic evaluations are true or false for all humans (or none), but not, say, true-for-me and false-for-you. By contrast, intersubjectivism does not say anything about non-human subjects - for instance, whether they have or know of aesthetic values, and if so, whether they share ours. ${ }^{13}$ Similarly, intersubjectivism is compatible with the idea

12 The resulting non-truth-apt evaluations are probably best understood in expressivist terms (cf. Gibbard 1990). Some expressivists have tried to establish some (non-substantial) notion of truth for evaluations (cf. Blackburn 1984 and Todd 2004) and hence align their accounts closer to the non-expressivist theories just mentioned which involve a similar notion of truth. However, this project has come under criticism (cf. Hopkins 2001), in part because a notion of truth may not be so easily had (cf. McDowell 1987). Expressivist accounts are often combined with the endorsement of some form of projectivism, according to which values are not real aspects of the world, but merely figments of our minds which we project onto the world (cf. Hume 1998, Blackburn 1984 and, presumably, Kant 1998). Besides, they may differ in respect to whether they accept that there are actually exemplifications of aesthetic values, or whether they prefer an eliminativist approach or some form of error theory concerning these values.

13 Cf. Budd 1995, 39f.. The choice of humanity as the hallmark of intersubjectivity is to some extent arbitrary. Perhaps it would be better to understand intersubjectivity in terms of (sufficiently large) cultures or communities - but only if these are specified in terms of 
that which aesthetic values objects exemplify is determined by, or otherwise depends on, the responses of only certain humans (e.g., experts, ideal judges, or subjects assessing objects under normal or optimal conditions). And it permits that only particular humans may have access to certain exemplifications of aesthetic worth.

Intersubjectivism is attractive because it explains in an easy and straightforward way why we take differing evaluations to be in conflict, ask ourselves and others involved for reasons for our assessments, enter discussions with them in order to come to agreement, either by trying to convince the others of our opinion, or by revising our own verdict, and so on. We do not treat our ascriptions of aesthetic values differently in these respects than, say, our ascriptions of shapes, wealth, talent in basketball, and other evaluative or or non-evaluative properties. Hence, the denial of intersubjectivism appears to imply admitting that there is some systematic error, or some misplaced demand on others to agree with us, involved in our aesthetic assessments. Of course, this is far from sufficient to settle the debate between intersubjectivists and their opponents. But what it illustrates is that giving up intersubjectivism should not be more than a last resort. ${ }^{14}$ And in response to this fact, many sentimentalists - not the least Hume and Kant - have tried to hold on to the intersubjectivity of aesthetic evaluations, at least as much as possible. ${ }^{15}$ In what follows, I would like to consider whether they can hope to succeed in this ambition.

\section{The challenge to sentimentalism}

8. As has often been observed (e.g., by Kant 1990, sections 36ff. and 56ff., and by Goldman 1995, 28f.), a particular challenge which they are facing is to show how it is possible to combine the idea of intersubjective aesthetic evaluations with the

linguistic, geographical and similarly evaluatively neutral factors, and not in terms of shared aesthetic sensitivities, tastes or emotional dispositions, given that this strategy would otherwise lead to some form of relativisation. Similarly, if the relevant class of subjects becomes too small, talk of 'intersubjectivity' would have lost most of its significance.

14 Even sentimentalists, who, at least to some extent, give up intersubjectivism in the face of the possibility of faultless disagreement, note how problematic this move is - for instance, because it contradicts our common intersubjectivist intuitions (cf. Goldman 1995, 37f.), or because "it may not be possible to establish any sufficient difference in the 'value-focus' of those who appear to be in disagreement" (Wiggins 1987b, 209; cf. also Wiggins 1987a, 181) for his idea to reject intersubjectivism in certain moral cases).

15 For instance, although Hume and Budd seem to allow for relativisation in certain cases - in Hume's case to age and culture, and in Budd's to ways of experiencing or understanding artworks (or to the underlying sensitivities and dispositions) - they nonetheless hold on to the idea that aesthetic evaluations are generally intersubjective (cf. Hume 1998 and Budd 1995, 42). 
possibility of faultless disagreement, all the while assuming a sentimentalist approach to aesthetic appreciation. This challenge may be developed in three steps.

The first step is the observation that our emotional responses to artworks and similar objects may differ - whether in quality or intensity, or whether intra- or interpersonally - even under conditions held to be suitable for epistemically adequate aesthetic appreciation. In particular, critics may come up with very different emotional reactions to objects, despite being of equally highly attentive and sensitive to the relevant marks of aesthetic merit, of similarly sufficient impartiality, expertise and training, and so on. For example, while one critic may feel excited by Les Demoiselles d'Avignon, another may respond with uneasiness, or awe, or nothing of the sort. And it appears that there need be no violation of any conditions on the epistemic appropriateness pertaining to aesthetic evaluations ${ }^{16}$ and, hence, no epistemic fault in either emotional response. ${ }^{17}$

According to the second step, the sentimentalist assumption that aesthetic evaluations are grounded on or constituted by the emotional responses at issue entails that, if these responses may differ in quality or intensity under the conditions ensuring epistemic adequacy in aesthetic assessment, our aesthetic evaluations may, too, differ under such conditions, whether in valence or in degree. The idea is that, if there are two distinct emotional reactions to a certain object under given circumstances, and if these responses lead to an aesthetic appraisal of the object, there will, as a result, also be two distinct aesthetic evaluations, one for each of the corresponding emotional responses. And given that this applies, in particular, to cases in which the appropriateness conditions for aesthetic assessments are satisfied,

16 I assume here that, if aesthetic evaluations are grounded on or constituted by emotional responses, the appropriateness conditions for the former include the aesthetically relevant appropriateness conditions for the latter. That is, according to sentimentalism, an evaluation is adequate from an aesthetic point of view only if the respective emotional response is as well. It thus is impossible to undermine the possibility of faultless emotions by introducing (allegedly) aesthetically relevant suitable conditions for emotions which are not part of the suitable conditions for aesthetic evaluations. Of course, the emotional responses involved may still be subject to appropriateness conditions which are aesthetically irrelevant (e.g., because they are impractical). But their inadequacy in this respect could not undermine the aesthetic appropriateness of the related evaluations.

17 Once it is accepted that there can be different emotional reactions to the same artwork (whether under the most suitable conditions or not), another important challenge arises. For it is conceivable that the respective critics may come, after extensive discussion and further scrutiny, to converge in their aesthetic opinions, without their diverging emotional responses disappearing. For instance, the judges of Picasso's painting may very well end up agreeing on its status as a masterpiece, despite continuing to emotionally react in different ways - say, with feelings of excitement, awe or uneasiness - to their experience of the work. Hence, it seems that there is a problem for sentimentalism not only with cases of disagreement, but also with cases of agreement: convergence in aesthetic assessment does not appear to be always due to convergence in emotional disposition or response. However, the pursuit of this second challenge to sentimentalism has to await another occasion. 
it follows also that there may be differing, but equally epistemically appropriate aesthetic evaluations of one and the same object.

The challenge arises now from adding the third step that such differing evaluations may very well be in conflict with each other. Two evaluations stand in conflict with each other just in case they assign incompatible values to the same object (considered at a specific moment in time). And two values are incompatible just in case a single object cannot exemplify both at the same time. Accordingly, assuming that something cannot be both boring and exciting at the same time, the two respective assessments are in conflict with each other. ${ }^{18}$ But as it seems, they may not have to differ in their epistemic appropriateness. Similarly, in the example about Picasso's painting, it may be possible that the diverging emotional responses give rise to conflicting aesthetic assessments of the work. For instance, it seems plausible to maintain that awe is linked to a different aesthetic value - if not in valence, at least in degree - than uneasiness. And the absence of any relevant emotion in one of the critics is presumably related to an altogether different value, or perhaps even to the absence of any. The challenge to sentimentalism can then be formulated in terms of the demand to show how it can satisfactorily handle the possibility of such cases of faultless disagreement - that is, of such cases of conflicting aesthetic evaluations, none of which needs to be at fault from an epistemic perspective.

If intersubjectivism is given up, this challenge can presumably be met with ease which is one reason why the denial of intersubjectivism may become quite attractive for a sentimentalist (cf. Goldman 1995, 26ff.). If objects would really be of different aesthetic merit for different people - because, say, the fittingness of aesthetic assessments, or the exemplification of aesthetic values, would be relativised to distinct groups of human beings - then there would cease to be any genuine conflict among differing assessments, since there would be no incompatibility any more between the aesthetic values ascribed by the various critics (and at various times, and so on). One and the same work could without a problem be boring-for-me and exciting-for-you, or graceful-for-me and insipid-for-you, or a masterpiece-for-me and no masterpiece-for-you; and one and the same aesthetic assessment (e.g., that a given work is beautiful) could equally unproblematically be true-for-me and false-foryou (assuming that it makes sense to speak of relativised values, exemplifications or truth-values). There might thus be no conflict between aesthetic evaluations, once intersubjectivism is given up.

But of course, the question remains whether sentimentalist can hold on to

18 Of course, there may be many other and independent ways in which evaluations or the underlying emotions may be in conflict (cf., e.g., de Sousa 2003 and 2007). 
intersubjectivism and still satisfactorily answer the raised challenge. I will argue that they cannot; and I will do so by looking in turn at two different strategies: to accept the possibility of faultless disagreement and to try to show that it is harmless (cf. sections 9-17 below); or, alternatively, to argue that there is no such possibility (cf. sections $18-20$ below). ${ }^{19}$

\section{Accepting the possibility of faultless disagreement}

9. While Hume, Kant and other sentimentalists have tried to rescue intersubjectivism by making plausible that our aesthetic evaluations and the related emotional responses would - at least under suitable conditions - converge (cf. the discussion below), it has recently become much more common to accept the possibility of faultless disagreement, both in conjunction with and independent of sentimentalism, and regarding both aesthetic and other values. A sentimentalist (and, incidentally, also a denier of intersubjectivism) in aesthetic matters, who endorses the possibility of conflicting appropriate assessments, is Alan Goldman. He claims that even the satisfaction of the most ideal conditions for aesthetic appreciation cannot ensure sameness in evaluative dispositions and opinions:

[One] cannot explain all disagreement as resulting from deviance from ideal critics or from borderline areas of vague terms. Instead, some disagreement reflects the fact that differences in taste persist through training and exposure to various art forms. (By 'taste' here I refer not only to different preferences but also to different judgements of aesthetic worth...). Even ideal critics will disagree in their ascription of evaluative aesthetic properties... (Goldman 1995, 36f.)

And assuming that non-evaluative features figure as supervenience bases for aesthetic values, he continues to argue that different critics of equally high standard may respond to the same set of non-evaluative features of an object by ascribing different aesthetic values to the object:

19The denial of the idea of appropriateness would not help to answer the challenge to sentimentalism. All evaluations would then equally reflect the aesthetic merit of objects (i.e., would, in some sense, be equally justified). And since many of them would stand in conflict with each other, giving up either intersubjectivism or sentimentalism would be the only options available. Indeed, the only hope to rule out the possibility of faultless disagreement is to hold on to the appropriateness of aesthetic evaluations and to try to show that appropriate assessments converge (cf. the discussion below). 
A painting with gently curving lines may be graceful to one critic and insipid to another. (Goldman 1995, 138)

Likewise, Wiggins, who considers and seems to tentatively defend a version of sentimentalism concerning moral - and presumably also aesthetic (cf. Wiggins 1987b, 199) - values, accepts the possibility of disagreements which cannot be resolved on the grounds that all but one verdict are inappropriate in some way or another:

In truth, whatever difficulties there are in the possibility of irresoluble substantive disagreement, no position in moral philosophy can render itself simply immune from them. We should not tumble over ourselves to assert that there is irresoluble substantive disagreement. We should simply respect the possibility of such disagreement, I think, and in respecting it register the case for a measure of cognitive underdetermination. (Wiggins 1987b, 210)

And finally, Hopkins argues that, if one accepts (as he seems to do himself) a broadly sentimentalist approach to aesthetic evaluation, as well as that testimony does not provide us with (much) reason to keep or change our own aesthetic assessments, then one should also endorse a position which combines the sentimentalist view with an embrace of the possibility of conflict among epistemically adequate evaluations. For, according to Hopkins, only such a position can hope to explain the assumed fact about the relation between testimony and aesthetic appreciation. ${ }^{20}$ Hence:

So we must abandon Kantian orthodoxy and allow that two subjects can be warranted in holding different, but genuinely conflicting, beliefs about something's beauty. [...] This is made tolerable by the separateness of the rational subjects in question. [...] The crucial notion, I suggest, will be that of a sensibility, a set of dispositions determining one's response, pleasure or otherwise, to the aesthetic object. Different subjects may be equally warranted in their conflicting judgements of a thing's beauty because the pleasure of each is in part determined by her sensibility, and sensibilities differ. (Hopkins 2000, 233)

These different quotations all illustrate a recent tendency to acknowledge, or at least to consider very seriously, the possibility of faultless disagreement in aesthetic

20 But Hopkins is also inclined to hold on to the intersubjectivity of aesthetic evaluations. Accordingly, his considerations about the view, which accepts the possibility of faultless disagreement in aesthetic matters are not without doubts about its tenability. In particular, he notes - but does not give up the hope of finally being able to avoid - the problem that the acceptance of this possibility might lead to an account which is in tension with the common assumption of the intersubjectivity of aesthetic evaluations (Hopkins 2000, 233 and 235f.). 
matters. And although they do not prove that this possibility really obtains, they add at least to the initial plausibility of its assumption.

The impact of the possibility of faultless disagreement

10. But how should or could an intersubjectivist sentimentalist react if he indeed accepts that faultless disagreement in aesthetic matters is - at least sometimes possible? Given that he wants to hold on to the intersubjectivity of aesthetic evaluations, the most plausible option - as suggested by Budd and others ${ }^{21}$ - is for him to accept that we should refrain from aesthetic assessment if confronted with concrete cases of conflict among epistemically appropriate evaluations:

If there can be faultless differences in taste, both of two opposed faultless aesthetic judgements will be false - in which case someone who is aware of the possibility of an opposed faultless response might be wise not to express her own response in the corresponding aesthetic judgement. (Budd 1999, 308)

The underlying reasoning is the following. Two conflicting evaluations assign different values to the same object of which it can exemplify at best one (at the particular time in question). Hence, at best one of the two evaluations can be fitting (e.g., true) in the sense of actually reflecting the aesthetic worth which the object has. Applying this result to epistemically adequate evaluations, it follows that at least one of two epistemically appropriate, but conflicting evaluations has to be non-fitting (e.g., false). Furthermore, we cannot tell which of the two assessments is non-fitting, and which fitting (if not both are non-fitting). Their epistemic appropriateness cannot any more be our guide to their fittingness, given that both are equally sufficiently appropriate from an epistemic point of view. And there could not be some additional and so far unnoticed evidence for the fittingness of one evaluation or the nonfittingness of the other, for this would mean that neither assessment would be epistemically adequate due to their violation of the requirement to take into account all relevant evidence. Hence, we should refrain from forcing a conclusion about which evaluation is fitting, that is, reflects the actual aesthetic merit of the object in question and, therefore, endorse neither of the two assessments.

Of course, we might not be aware of the possibility of a faultlessly conflicting

21 Wiggins, for instance, suggests even "[giving] up on the predicate" in this case (Wiggins 1987b, 209). 
evaluation with respect to one of our concrete actual assessments and, hence, might fail to refrain from judgement in such a case. But we would still be rationally required to do so. Besides, as Budd notes in the quote, the mere possibility of an appropriate alternative verdict is already sufficient to undermine the epistemic standing of a given actual evaluation. No one needs to actually come up with the conflicting opinion for it to have an impact on the epistemic appropriateness of the already existing assessment. That is, it is the possibility of faultless disagreement, which functions as a defeater, and not its actuality.

Wiggins proposes another strategy to deal with concrete instances of faultless disagreement, namely to "remain undeterred" and to "persevere as best as we can in the familiar processes of reasoning, conversion, and criticism - without guarantees of success, which are almost as needless as they are unobtainable" (Wiggins 1987b, 209 and 210). But it is not clear what this could mean, apart from ignoring the problem and continuing in one's evaluative practices as if there were no possibility of faultless disagreement. Success would not only not be guaranteed, it would be impossible. For even if some of us were to end up with fitting assessments reflecting the aesthetic values of the objects concerned, we would not be able to know this, since we would still not be able to identify the fitting and the non-fitting evaluations among all epistemically adequate ones. Also, Wiggins' hope cannot be that, in the end, there will be agreement, given that he maintains - in the longer passage quoted further above - that we should take the possibility of "irresoluble substantive disagreement" serious. Wiggins' proposal might still amount to good practical advice. But it does not tell us anything about how to theoretically handle specific cases in which there is the possibility of two conflicting appropriate evaluations.

\section{The problem of the ubiquity of possible faultless disagreement}

11. Now, if the possibility of faultless disagreement would be widespread (i.e., arises in many relevant cases) or even universal (i.e., arises in all relevant cases), this would have serious consequences for the epistemic standing of both the aesthetic evaluations and the emotional responses which ground or constitute them. ${ }^{22}$ Hence, a intersubjectivist sentimentalist faces the difficult task to limit this possibility only to a few cases, that is, to a few actual instances of aesthetic merit.

If the possibility of faultless disagreement would turn out to be universal - that is, if

22 Cf. Hopkins 2000, 233 and 235, for similar, though less pessimistic worries. 
there is the possibility of the occurrence of a conflicting adequate opinion in the case of at least all actual occurrences of appropriate verdicts (whether they occur in the past, present, or future) - then we should always refrain from aesthetic judgement, given that we could not distinguish any more the fitting evaluations from the nonfitting ones among the set of epistemically appropriate responses. But this would have the (absurd) consequence that we actually would not have any adequate or reliable access to instances of intersubjective aesthetic values - presumably, either because there were none, or because our emotional responses meant to ground or constitute our aesthetic evaluations would not put us in proper contact with them. The first would mean that sentimentalism is pointless; the second, that it is false. Hence, the intersubjectivist sentimentalist should deny that the possibility of a conflict among epistemically appropriate evaluations holds universally.

But he should also resist the assumption of a widespread possibility - that is, of the possibility of a faultlessly disagreeing response with respect to at least many of all the actual past, present or future occurrences of adequate aesthetic assessments. As I have illustrated further above, it is common for sentimentalists to maintain that, once our relevant emotional responses occur under conditions ensuring the epistemically appropriate appreciation of objects, they do - or at least are likely to ground or constitute aesthetic evaluations which are fitting, that is, indeed reflect the aesthetic worth of the object concerned. But if the possibility of faultless disagreement would be widespread, there would be many justified aesthetic assessments which are non-fitting, given that at best one of several conflicting adequate evaluations could be fitting. And this would undermine the postulated link between epistemic appropriateness and fittingness (e.g., the truth-conduciveness of the former): if many emotional responses would give rise to non-fitting aesthetic evaluations, despite being epistemically adequate and thus possessing the required justificatory potential, they would loose their general capacity to render aesthetic assessments (likely to be) fitting - and, hence, their related capacity to ground or constitute evaluations which potentially reflect actual instances of aesthetic worth. The intersubjectivist sentimentalist should therefore argue also against the widespread possibility of faultless disagreement concerning aesthetic merit - at least if he is assuming that epistemic appropriateness is either constitutive of or conducive to fittingness.

However, such sentimentalists may still choose to accept the possibility of a conflicting justified opinion with regard to only some actual instances of epistemically adequate aesthetic evaluations. Indeed, many intersubjectivist sentimentalists have 
opted for this route (cf., e.g., Hume 1998 and Budd 1999). But, in order to avoid the problems outlined above, they should then also reject the further thesis that, given that faultless disagreement in aesthetic matters is possible in some actual cases of aesthetic assessment, it is also possible in many or even all such cases. The sentimentalist in question can try to resist this further thesis in two ways. First, he can claim - with respect to the first step of the challenge outlined above - that the possibility of diverging emotional responses even under conditions suitable for epistemic appropriateness is limited to only a few actual instances. And second, he can claim - with respect to the third step - that the possibility of a conflict among diverging, but epistemically appropriate evaluations is limited to only a few actual instances. $^{23}$ I will discuss each option in turn (cf. sections 12-13 and sections 14-16, respectively).

The ubiquity of possible faultless divergence among emotional responses

12. The first alternative turns out to be untenable, once a closer look is taken at what is responsible for the possibility of a divergence among our emotional responses to aesthetic objects. A diagnosis of this form is not often provided, even by sentimentalists who accept the possibility of differing emotional responses under conditions which ensure the justification of the related evaluations. What is crucial here is the middle position with respect to rational responsiveness and determination, which emotions and emotional responses take up in relation to other mental episodes and states, at least if fully rational subjects (which moreover are competent in their use of concepts, and so on) are concerned. Sensations, perceptions and basic desires (such as hunger), for instance, are not responsive to reasons at all, even in fully rational subjects. They occur and disappear merely due to causal mechanisms, and independently of any reasons of which we may be aware. In contrast, judgements, beliefs and instrumental desires are sensitive to reasons, at

23 A third strategy would be to accept the widespread or universal possibility of faultless disagreement relative to our actual aesthetic evaluations, but to discount its epistemic significance for the latter - for instance, because this possibility is not 'real' enough, that is, is too remote from how things actually are and therefore seldomly or never actually realized. However, the relevant possibility of a difference in the intervening causal factors concerns typically the personalities, moods or habits of the subjects in question (cf. section 12f. below) and should thus not count as too remote or 'unrealistic'. And moreover, even if the possibility would be only remote, there would presumably be the need to relativise the exemplifications of aesthetic values, or the truth-values of aesthetic assessments, at least in the distant worlds involved. But relativisation is, if at all, an essential feature of the entities concerned. Thus, if they would be relativised in some possible world, then they would be relativised in all worlds, including the actual. 
least in fully rational subjects. More specifically, in such subjects, they are formed solely in response to reasons; and no merely causal factors are involved in the determination of their occurrence and content. ${ }^{24}$

Emotional dispositions and responses seem to be located somewhere between these two extremes, some perhaps closer to perceptions and the like, and others maybe closer to judgements or beliefs and the like. As I have already discussed, our emotional responses are often responding to rational forces. We become aware of the danger of walking near the edge of a cliff and start to feel frightened; and we discover that (certain) dogs are agressive and dangerous and begin to develop the disposition to fear them. ${ }^{25}$ But our emotional responses are in many cases only partly determined by reasons. Merely causal factors are also often involved, both in the acquisition of emotional dispositions and in their manifestation in the form of occurrences of emotional responses - and even, as it seems, in fully rational people. For instance, character traits seem to be important. A generally timid person is more likely to develop a disposition to fear dogs than a nervy one. Habits may also become relevant. Having to regularly work at great heights may decrease one's tendency to become frightened, even though one still believes it to be dangerous each time one goes up. Similarly, other factors - such as associations, moods or other emotions (cf. Goldie 2000, 75f.) - may have such a merely causal impact on our emotional disposition and responses. But due to its non-rational nature, such an impact is compatible with the emotions in question satisfying the constraints on their rationality. Hence, the many emotions, which are only partially responsive to reasons, may count as rational even if they are influenced by non-rational factors.

Wiggins seems to make a very similar point with respect to the possibility of two differing and conflicting moral verdicts, with which we may come up despite being "not distinguishable in any of the relevant respects such as the capacities, obligations, commitments, etc., that deliberation can treat as fixed" (Wiggins 1987a, 181, n. 43), and which can survive "scrutiny of everything in the circumstances and

$24 \mathrm{I}$ assume here that it is part of being a rational person that one forms a judgement, belief or desire just in case one has reason to do so, and no undercutting or overriding contrary reasons. The intimate links between the formation of judgements, beliefs or desires in rational subjects and their reasons for forming them have been noted and described by Peacocke 1992 and Smith 1994, among others. Of course, we may still come to form judgements, beliefs or desires in irrational ways - for instance, when forming them partly or entirely due to causal factors (e.g., certain feelings, moods, or drugs). And similarly, fully rational subjects may still differ in their judgements, beliefs or desires, despite being aware of the same reasons. Such differences may concern the degree of credence, the intensity of longing, the threshold of when reasons become compelling, and so on. Thanks to an anonymous referee for pointing this out to me.

25 I assume here that the sentimentalist will accept that the facts providing us with reasons for emotional responses provide us at the same time with reasons for the corresponding evaluations (cf. Goldie 2004 and 2007). 
scrutiny of all other deliberatively admissible facts" (ibid., 181). As he suggests, even if some (say, causal) difference between the two cases is assumed (as seems plausible), these underlying (causal) factors need not have any rational impact on our diverging verdicts:

Surely there must be something about case $C_{1}$ that made that turn out the other way and differently from $\mathrm{C}_{2}$. Perhaps. Let me not quarrel here with this well-worn dogma. But that which explains the difference in outcome [...] need not impinge upon our grounds for endorsing one verdict in $\mathrm{C} 1$ and the other verdict in $\mathrm{C}_{2}$. (Wiggins 1987a, 181f.)

In short, the epistemic appropriateness of our evaluations is a matter of reasons alone, but our relevant emotional responses are often not. In many cases, the reasons underdetermine the emotional responses. And in these cases, even if there is no difference in rational impact and hence in epistemic standing, non-rational factors can - and are perhaps even likely to - lead to diverging emotional responses.

13. The sentimentalist might still insist that cases of emotional responses, which involve some non-rational influence, should count as inappropriate, at least according to the requirements for justification in aesthetic assessment. The idea would be that epistemic appropriateness excludes such non-rational forces and, hence, ensures - as in the case of judgements, beliefs or instrumental desires - convergence in rational response.

However, it is doubtful that all possible kinds of merely causal influences on our relevant emotional responses should count as undermining the justification of the related aesthetic assessments. In the example of Picasso's painting, the difference between the various emotional responses is due to a difference in such non-rational forces. But it seems equally appropriate, from an aesthetic point of view, to react to this particular artwork with excitement, awe, or uneasiness. ${ }^{26}$ Similarly, we do not take all non-aesthetic emotions to be inadequate solely on the ground that they have been influenced by our personalities, habits, and so on. It seems that the sentimentalist rejoinder would simply render too many emotional responses and corresponding evaluations - whether in aesthetic or other matters - to be inappropriate.

26 This seems to be an instance of the more general problem - as it has been noted by Levinson 2002 with respect to Hume's account - to justify, from an aesthetic point of view, the selection of a particular set of conditions (and not another one) as those which ensure epistemic appropriateness in aesthetic appreciation. 
Then, it is doubtful that non-rational factors have any significant bearing on aesthetic appropriateness in the first place. As it seems, the epistemic appropriateness of aesthetic evaluations is - just like the epistemic standing of judgements, beliefs or instrumental desires, but unlike the epistemic adequacy of sensations, perceptions or basic desires - exclusively rational in nature, that is, solely a matter of reasons and rational considerations. This strict focus on reasons is reflected in the fact that, when asked to justify our aesthetic verdicts, we exclusively refer to features of the objects concerned which are (or which we take to be) aesthetically relevant reasons. And it is also illustrated by the fact that the conditions ensuring the epistemic appropriateness of aesthetic evaluations are traditionally unconcerned with the exclusion of non-rational influences, and instead merely demand the correct assessment of all aesthetically relevant reasons, as well as the disregard of all other kinds of reasons (e.g., purely sentimental ones). ${ }^{27}$ However, if the epistemic appropriateness of aesthetic assessments is solely a matter of reasons, the presence of merely causal factors cannot undermine it, as long as it is true that all the rational requirements are fulfilled.

A final difficulty arises out of the phenomenon of the relative cognitive impenetrability of our emotional responses (cf. Goldie 2000). Emotional responses are relatively cognitively impenetrable (or inert) in the sense that they often tend to resist the immediate pressures of rational considerations. Although our emotional responses are in general responsive to reasons, this responsiveness is not always effective, or at least not directly. Belief in the irrationality of a certain emotional responses may cause it to vanish straight away. But it is more often the case that emotional responses remain existent and manifest, at least for a while, even if one is aware of there being no good reason for their manifestation. For instance, that my lover has succeeded in convincing me of the fact that she is not having an affair may well have no (immediate) influence on my feeling jealous of the suspected competitor. Or my knowledge of the harmlessness of spiders need not prevent me from feeling fear when I am confronted with one. Again, this appears to place emotional responses between perceptions, sensations or basic desires, on the one hand, and judgements, beliefs or instrumental desires, on the other.

The relative cognitive impenetrability of emotional responses raises two particular problems for the sentimentalist reply under discussion. The first is to explain why it is possible, and common, with respect to emotions (and impossible or at least very rare with respect to judgements, beliefs or instrumental desires, even in subjects who are

27 This is true even of impartiality requirements, such as Kant's disinterestedness (cf. Kant 1985, sections $2 \mathrm{ff}$.)). 
not fully rational). The best explanation of this fact seems to be that there can - and often do - exist non-rational forces, which compete with and overcome the rational ones at work. When we know that something is not dangerous and still fear it, what happens is that the rational force of our knowledge is trumped by some causal factors which sustain or continue to bring about our feeling of fear. The second problem is to make plausible that all occurrences of cognitive impenetrability are inappropriate or irrational, at least from an aesthetic perspective. For if they are not, such occurrences will constitute further cases of faultlessly disagreeing emotional responses. Consider the cognitive impenetrability of perceptions. If we experience the Müller-Lyer illusion, but are aware of the underlying mechanisms and of the fact that the lines are nonetheless of the same length, it would be odd to describe us as irrational. Of course, our perceptual experience is mistaken. But this mistake is not of a rational sort. Likewise, if we are afraid of something that we know to be completely harmless, and if we perhaps also know why our fear persists, our response does not seem to be irrational either. ${ }^{28}$ In particular, even our best attempts at education or training need not lead to the desired responsiveness (cf. Goldie 2000, 110). Hence, it still needs to be motivated that emotional cases of cognitive impenetrability are always inappropriate - and, in the relevant cases, especially from an aesthetic point of view.

The conclusion should therefore be that the conditions on the justification of aesthetic evaluations cannot guarantee a sameness in emotional responses or dispositions. There is always the possibility of differing responses, given that there is a great variety of causal factors which may become effective in the establishment of emotional dispositions or in their manifestation in concrete cases. Hence, in the context of adequate aesthetic assessment, there is likewise always, or at least in many cases, the possibility of a divergence among our emotional responses.

\section{The ubiquity of possible faultless disagreement in aesthetic appreciation}

14. But, as I mentioned above, there is a second option of resisting the further thesis that the possibility of faultless disagreement in some actual cases of aesthetic assessment implies its widespread or even universal possibility. The aim is now to limit this possibility on the level of aesthetic evaluations, rather than on the level of

28 At least, we appear to be far less in the wrong than in the case in which we fear something harmless while taking it to be dangerous, or in the case in which we fear something harmless without being aware of our tendency to fear things of this kind despite their harmlessness (cf. Goldie 2000, 75f.). 
emotional responses. The idea is that, even if it is accepted that for many or even all actual and epistemically appropriate aesthetic assessments of an object there can be diverging evaluations, and also that for some of these cases there is the possibility of a genuine conflict in assessment, it does not automatically follow that there can be conflicts in more than a few of the cases of divergence. And simply assuming the ubiquitous possibility of conflict among epistemically adequate evaluations seems to beg the question with respect to the sentimentalist. ${ }^{29}$ As Budd puts it:

[One can] make the exceptionally strong claim that with respect to any object and any aesthetic property ideal critics might faultlessly disagree, or merely that, for each aesthetic property, it is possible for there to be cases in which there is no consensus among ideal critics as to whether a certain object possesses that property. This weaker claim might well be true. But to establish in the case of a particular [aesthetic value] that it is possible for there to be a set of nonevaluative properties suitable to be the basis of that [value] which is such that there can be faultless disagreements of taste among ideal critics, it would be necessary to show that the constraints imposed on the base properties by the nature of the aesthetic [value] and the criteria for qualifying as an ideal critic do not guarantee a consensus in aesthetic judgements. (Budd 1999, 307).

Budd's point applies even if the proponent of the ubiquity of possible conflicts among justified assessments of aesthetic merit limits his claim merely to the widespread possibility of faultlessly disagreeing opinions with respect to actual evaluations. Accordingly, the defender of the challenge to sentimentalism has to demonstrate, or at least to render very plausible, that a conflict among differing appropriate assessments is possible in more than a few cases. And this can indeed be achieved. If the diverging evaluations are concerned with the overall aesthetic merit of the object in question (e.g., its being, or not being, a masterpiece), they have to be in conflict, simply because an object can possess only a single intersubjective overall aesthetic

29 Indeed, as has been pointed out to me by an anonymous referee, a sentimentalist might more generally object that what we are concerned with here is establishing merely the epistemic possibility of faultless disagreement, but that, for all that we know, convergence under optimal conditions seems as epistemically possible as divergence. But even if the first half of this objection is true, the burden of proof lies still with the sentimentalists, and for two reasons. First, they aim at positively establishing the claim that emotions can justify evaluations. And, as I try to argue in this essay, they can achieve this aim only if they either accommodate or positively rule out the metaphysical possibility of faultless disagreement, and not by merely casting some doubt on it. And second, in the light of our actual evidence about how emotions get influenced by very differing causal factors and, as a result, actually differ a lot, it seems much more likely that they will diverge than converge, even under the most optimal conditions. For the criteria for optimality concern primarily, or even solely, rational factors, and not causal ones (cf. section 13 above). 
value at a given time. An object cannot truly and simultaneously be both a masterpiece and no masterpiece. At best, it can simultaneously be both a masterpiece-for-me and no masterpiece-for-you, or its possession of the property of being a masterpiece may be true-for-me and false-for-you. Accordingly, intersubjective aesthetic assessments - in fact, whether they are justified or not - are in conflict with each other whenever they ascribe different overall values to the same object.

15. The intersubjectivist sentimentalist can therefore claim merely that the possibility of a conflict among differing, but justified evaluative responses occurs on more specific levels of aesthetic appreciation (and even there only rarely, for that matter). These levels are concerned with the recognition of (often partially descriptive) aesthetic values which, although they contribute to the overall merit of their bearers, are either local by pertaining solely to certain parts of the objects (e.g., the beautiful left panel), or aspectual by concerning only certain aspects of the worth of the objects (e.g., the elegance or inventiveness of its drawing). ${ }^{30}$ But due to this limitation of the acceptance of possible cases of faultless disagreement, sentimentalism runs into some serious difficulties.

First, the challenge to sentimentalism still undermines the epistemic standing of our aesthetic evaluations and related emotional responses if these are concerned with the overall assessment of objects. Given that many, if not all, of our respective responses occurring under epistemically faultless conditions permit differing reactions, and given that diverging overall evaluations have to be in conflict, there is indeed the widespread or even universal possibility of conflicting, but adequate assessments of overall aesthetic merit. Hence, the sentimentalist view at issue has the untenable consequence that we should refrain from making overall aesthetic assessments.

Second, the number of cases, in which faultless disagreement about the overall worth of an object is possible, is presumably large enough to threaten to undermine also the epistemic standing of our aesthetic evaluations and emotional responses in general, that is, independent of the specificity of value involved. This presupposes that we do not distinguish between overall and more specific assessments when we consider the epistemic status of our evaluations. That is, if we should refrain from making the one kind, we should also refrain from making the other kind of assessment. Any disjunctive approach to this problem, on the other hand, would call

30 Perhaps the more specific values differ from the overall ones also in that the former, but not the latter, are merely prima facie and open to be overridden or undermined by other more specific values of their bearer (cf. Goldie 2007 for a very similar distinction). 
into question our epistemic practice of deriving overall values from more specific ones, possibly rendering the former unknowable. And it would cast doubt on the classification of both as values of broadly the same kind (i.e., as aesthetic).

Third, the claim that most diverging (appropriate) aesthetic assessments on a more specific level are not in conflict seems implausible. Considering again Goldman's example, the aesthetic values of being graceful and insipid do not merely seem to differ, but also to be incompatible with each other (if only in the descriptive aspects of these evaluative properties). As it appears, a painting - or some part of it - cannot be graceful and insipid at the same time. And many other more specific aesthetic values - such as being gaudy and calm, or balanced and unsteady - seem to stand in similar conflicts with each other. Hence, it appears likely that many (adequate) aesthetic evaluations are incompatible, despite not concerning the overall merit of an object.

And fourth, the sentimentalist would still have to provide an account of the fact that we so often take our evaluations to be in conflict with each other, even at the level of local or aspectual values. We do think that many of our respective assessments are in conflict, and that there is a genuine need to settle the dispute. For instance, if someone takes a painting to be insipid which we take to be graceful, we tend to answer back and try to convince him of our opinion, or at least to bring him to disclose the reasons for his assessment. And if we cannot find any fault with any of the diverging responses, even after long and detailed scrutiny and discussion, and therefore eventually stop arguing, this happens usually simply because we do not know what to say any more, and not because we cease to think that there is something to argue about.

16. One interesting reply to this, as well as to the more general issue of how to deal with the seemingly possible conflicts among justified aesthetic evaluations, is to maintain that all what the possibility of differing evaluative responses shows is that we may not all have the same access to aesthetic values. The lack of intersubjectivity would thus turn out to be merely epistemological. This might perhaps be how Hume understands the seemingly subjective elements which he (perhaps a bit surprisingly) introduces into in his account: ${ }^{31}$

31 Thanks to Mike Martin for making me aware of this way of understanding Hume. According to a different reading, suggested to me by an anonymous referee, Hume may not intend to say here that differences in age and culture influence the aesthetic values of works (or our responses which determine these values), but instead that they influence only our presumably more personal practical - subjective preferences among the works with high aesthetic merit (e.g., whether we prefer masterpieces of romantic or of didactic poetry). If this alternative interpretation is right, Hume's position does not involve any kind of 
A young man, whose passions are warm, will be more sensibly touched with amorous and tender images, than a man more advanced in years, who takes pleasure in wise, philosophical reflections concerning the conduct of life and moderation of the passions. At twenty, Ovid may be the favourite author; Horace at forty; and perhaps Tacitus at fifty. Vainly would we, in such cases, endeavour to enter into the sentiments of others, and divest ourselves of those propensities, which are natural to us. (cf. Hume 1998, 150)

Perhaps there are indeed certain limits on which aesthetic value we can recognize at various stages of our life or development; and perhaps these limits are connected to the fact that our emotional dispositions are partly determined by factors, which uniquely pertain to each of those stages, and which inevitably change over time in conjunction with the related dispositions. This would mean that we would not always have, nor could acquire, the emotional dispositions required for the recognition of the overall aesthetic merit of certain objects, or of the more specific values contributing to this overall worth. For instance, the young may yet not be able to appreciate Tacitus, because the latter's writings leave him generally cold, or because he cannot grasp all the relevant specific merits of these writings.

But this epistemological approach to the divergence among our evaluative responses faces at least two serious problems. The first difficulty is that it does not seem to apply easily to cases in which there are two competing responses, rather than one response and an absence of one. What if the young is not left indifferent by reading Tacitus, but is bored by him, or even annoyed? If this would mean that he has access to a different overall aesthetic value than the old who enjoys the writings, then one of the two would have to be in the wrong, given that the works can posses only a single overall value. But there would be no epistemic reason to prefer one response over the other. If, on the other hand, the young's assessment would concern merely a different more specific value than that of the old, at least one of the two presumably the young - would not have access to the overall value of Tacitus' writings. For he would not have access to the more specific values which are only seen by the old, but which nonetheless contribute to the overall merit. And we would perhaps be happy to say that the young gets the overall value of Tacitus' works wrong; but not that he cannot even assess it. The second problem is that, to cover all cases of possible faultless disagreement, it would presumably have to be assumed

relativisation to age or culture, but still faces the challenge to sentimentalism outlined in this essay. 
that there are many aesthetic values (whether more specific or not) to which we do not have access at a given time in our life or development. But this would again, and again absurdly, mean that we would not have access to the overall merit of many works.

17. Besides, there is a further and independent problem for any sentimentalist position which assumes the possibility of faultless disagreement in certain, but not all cases: namely to answer the difficult question of which feature of us, or of the respective situations, or of the aesthetic values involved, is responsible for this restriction to certain cases. As it stands, it seems arbitrary that the possibility of faultless disagreement arises in certain cases - in which we should then refrain from aesthetic judgement - but not in others. As long as no satisfactory explanation of this postulated fact is provided, it seems more appropriate to allow for this possibility in all cases, if in any at all.

As a consequence, a sentimentalist should admit that, if faultless disagreement is possible in some actual cases of aesthetic assessments, than it is also possible in many or even all actual cases. Hence, to avoid the ubiquity of the need to refrain from aesthetic assessment, he should either give up intersubjectivism, or deny the possibility of faultless disagreement altogether.

\section{Denying the possibility of faultless disagreement}

18. Sentimentalist can deny the possibility of faultless disagreement and thereby reject the raised challenge as misguided in various ways. The traditional approach has been to undermine the first step of this challenge by arguing that there is no emotional divergence under suitable conditions. According to the Kantian approach (cf. Kant 1990, sections 20ff. and 36ff.), we all possess - presumably from birth on and as part of our common human nature - the same affective disposition to react with pleasure or displeasure, at least with respect to those responses which are relevant for aesthetic appreciation (i.e., we all possess the same 'taste'). The Humean approach (cf. Hume 1998), on the other hand, maintains that we may and usually do possess different relevant emotional dispositions, but that, under suitable conditions, the same dispositions will develop and become effective in all of us. The idea (or hope) is that raising the standards for the appropriateness of aesthetic evaluations will lead to a convergence among those emotional responses and verdicts living up to 
these standards. However, it is nowadays widely accepted that both approaches are bound to fail (cf., e.g., Budd 1995, ch. 1, Goldman 1995, 26ff., Zangwill 2001, ch. 9, and Levinson 2002). And their failure seems to be due, at least to a considerable extent, to the fact that our emotional responses are partly beyond rational influence, while the epistemic standards governing our aesthetic assessments do not concern non-rational, that is, merely causal factors (cf. section 13).

19. A different and more recent attempt to deny the possibility of faultless disagreement has been to question the second step of the challenge to sentimentalism by denying that the possibility of diverging emotional responses even under conditions suitable for epistemic appropriateness transfers to the related evaluations. $^{32}$ This amounts in fact to a denial of the possibility of differing aesthetic evaluations under those conditions. Budd suggests two ways in which this may be achieved. He describes the first in the following manner, treating evaluative properties here as dispositional:

If [...] crediting an object with the dispositional property only if it is such as to elicit the response from all the qualified viewers, [...] the absence of uniformity of response will imply that the object does not possess the aesthetic property in question.(Budd 1999, 306)

The central idea is to add a further condition necessary for epistemic appropriateness, in addition to the more substantial requirements already noted (i.e., the demands for full information, attentiveness, sensitivity, impartiality, experience, and so on). And this further condition states that an aesthetic evaluation is appropriate only if there is - or, alternatively, can be - no differing assessment when the more substantial conditions are satisfied. Budd seems to prefer the reading according to which only the actual occurrence of a second and faultlessly disagreeing evaluation would undermine the justification of the originally given assessment. But this does not help to undermine the possibility of faultless disagreement in cases in which a given adequate opinion is not actually confronted with a faultlessly conflicting verdict. For the fact that the latter does not actually occur does not

32 If the emotional responses are taken to be constituents, and the sole constituents, of the evaluations, the second approach becomes very similar to the first. Besides, another way of undermining the possibility of faultless conflict among various aesthetic evaluations is to reject the third step of the challenge to sentimentalism by denying that such assessments are ever in conflict with each other. But for the reasons already rehearsed in sections 14-16 above, this strategy is bound to fail with respect to ascriptions of both overall aesthetic values and more specific ones. See also footnote 27 for the discussion of a fourth way of trying to undermine the possibility of faultless disagreement. 
undermine its possibility. Hence, in this reading, the additional condition, together with the initial, more substantial set, does not suffice to rule out the possibility of faultless disagreement. But the other reading, according to which already the possible occurrence of another faultless, but conflicting evaluation would undermine the epistemic standing of the original assessment, does not fare better. For it would lead to a needlessly sceptical view on our ability to gain justified access to instances of aesthetic values, unless the possibility of faultless disagreement under the initial, more substantial conditions (without the newly added one) can be limited to a few cases. For if this possibility would be widespread, the additional condition would classify all the respective (and otherwise possibly adequate) aesthetic assessments as unjustified.

20. Now, Budd presents a second way in which the possibility of faultless disagreement among aesthetic assessments can be denied:

The second is to understand a judgement that ascribes [an aesthetic value] to a work as making no reference to ideal viewers but rather as claiming that the work uniquely merits a certain response, so that the response is the right response. [...] In fact, the second of the two strategies would appear to be more plausible. [...] Accordingly, a response-dependent account of judgements that ascribe [aesthetic values] should represent the content of such a judgement as being that the item to which the property is ascribed is such that the evaluative response integral to the property is the appropriate response to the item, the judgement being true if and only if any competing response is indicative of a defect in a person who responds to the item in that manner or an inadequacy in the person's engagement with the item. (Budd 1999, 307f.)

What Budd proposes is that certain evaluative responses are appropriate, but others not, because only the former are rendered adequate by the actual values of the objects concerned. And aesthetic values render appropriate precisely those evaluations which stand in a correspondance relation to them - where the correspondance presumably consists in the fact that the values have to be elucidated in terms of the responses in question, and that the responses assign these values to the objects at which they are directed. This suggests that evaluative responses are appropriate only if their objects actually exemplify the corresponding values, and that what is at issue is therefore the fittingness of aesthetic assessments. Hence, the actual presence of the value is a condition on fittingness, but not necessarily on 
epistemic appropriateness. On the other hand, Budd's proposal involves also the claim that the exemplified values merit or justify the corresponding evaluative responses. And this suggests that what is at issue is the epistemic appropriateness of aesthetic assessments. This duality in the proposal remains unproblematic only if an account of aesthetic appreciation is endorsed which claims that epistemic appropriateness coincides with fittingness. Hence, Budd probably has (or should have) such a position in mind. ${ }^{33}$

But in any case, his second proposal turns out to be very similar to the first in that it likewise involves the key claim that the satisfaction of the conditions on epistemic appropriateness by more than one conflicting evaluation renders all of them unjustified. The difference between the two proposals concerns the issue of which factors are relevant for epistemic adequacy - the satisfaction of the original, more substantial conditions in the first case, or the presence of a justifying link between the exemplified value and the response in the second. But this means also that the second proposal faces, basically, the same difficulties as the first.

\section{Conclusion}

21. What the preceding considerations have been intended to illustrate is that intersubjectivist sentimentalists can neither hope to be able to accommodate the possibility of faultless disagreement, nor hope to be able to undermine this possibility. The conclusion is that sentimentalists, in response to the challenge to their position, should simply reject intersubjectivism (and thereby reject the second step of this challenge). However, in the light of the potential unattractiveness of giving up intersubjectivism, it is perhaps better to understand this conclusion as a motivation to reject the view that sentimentalism may provide a satisfactory account of the epistemology of aesthetic appreciation, and to begin to search for a more promising

33 Budd's second proposal has also some affinities to accounts which do not take epistemic appropriateness to be always sufficient for fittingness. The proposal appears to replace the verdicts of ideal judges (i.e., our epistemically best opinions) with the actually exemplified values as determinants of the standard for the appropriateness of aesthetic evaluations. This suggests a shift from projected values to ones which are cognizable as proper parts of reality. Indeed, Budd may seem to have adopted the talk of 'objects meriting responses' straight from defenders of a substantial notion of truth which is not reducible to epistemic appropriateness (cf. McDowell 1983 and 1985, and Wiggins 1987b). But perhaps this ambiguity in how to understand Budd's second proposal just illustrates that both it and McDowell's and Wiggins' positions resist the usual classifications - or, more pessimistically and uncharitably, involve an unavoidable incoherence. 
alternative..$^{34^{*}}$

\section{REFERENCES}

Bender, J. 1995, "General but Defeasible Reasons in Aesthetic Evaluation: The Generalist/Particularist Dispute", Journal of Aesthetics and Art Criticism 53, pp.379-392

Blackburn, S. 1984, Spreading the Word, Oxford: Clarendon Press

Budd, M. 1995, Values of Art, London: Penguin

Budd, M. 1999, "Aesthetic Judgements, Aesthetic Principles and Aesthetic Properties", European Journal of Philosophy 7, pp. 295-311

D'Arms, J. and Jacobson, D. 2000, "The Moralistic Fallacy: On the 'Appropriateness' of Emotions", Philosophy and Phenomenological Research 61, pp. 65-90

D'Arms, J. and Jacobson, D. 2003, "The Significance of Recalcitrant Emotion (or, Antiquasijudgmentalism)", Philosophy, suppl., Proceedings of the Royal Institute of

34 One possibility is that such a theory may take evaluative judgements to be perceptual or intuitive. Goldie 2007, for instance, argues that we can literally perceive instances of (moral) merit, even if only with respect to partly descriptive, and thus more specific, values. However, most of what Goldie says while elucidating and defending his view seems entirely compatible with an intuitionist approach - as appears to be true of much of McDowell's writings (cf. the talk of 'perception' in his 1983 and 1985), which have partly inspired Goldie's work. In my view, it seems more plausible to take genuine intersubjective evaluations - in contrast to merely subjective preferences - to be the result of reasoning (cf. Bender 1995). But, as Goldie 2007 suggests, the two outlooks may perhaps be combined: it may be the case that, while the justification of intersubjective assessments is primarily a matter of reasons, these evaluations can nonetheless be psychologically based on - or 'motivated' by - perceptions or intuitions alone. It seems to me, however, that this makes sense only if it is in addition assumed that reasoning is still not only epistemologically, but also psychologically prior to perception or intuition - notably in that we can ultimately acquire the ability to see or intuit instantiations of value only on the basis of a prior recognition and assessment of reasons for evaluation (cf. the case of a chess-player who, by reasoning about positions of a certain kind, learns how to immediately tell which move is best in positions of that type; cf. Goldie (2007) for this example and related discussion).

* Part of this paper has been presented at the 'Emotions and Rationality in Practical Philosophy' conference at the Universities of Neuchatel and Bern, as well as at a workshop at the University of Fribourg. I would like to thank the respective audiences for their helpful comments, especially Davor Bodrozic, Julien Deonna, Peter Goldie, Kevin Mulligan, Gianfranco Soldati, and Ronnie de Sousa. For extended discussions of the issues raised in, or detailed comments on previous drafts of, this essay I am very grateful to Malcolm Budd, Mike Martin, Elisabeth Schellekens, Nick Zangwill, the editors of this volume and of dialectica, and their anonymous referees. I would also like to thank the Swiss National Science Foundation for sponsoring me during my work on this paper. 
Philosophy, pp. 127-146

Döring, S. 2007, "Seeing What to Do: Affective Perception and Rational Motivation", dialectica 61 , pp. \#\#\#

Gibbard, A. 1990, Wise Choices, Apt Feelings, Cambridge (Mass.): Harvard University Press

Goldie, P. 2000, The Emotions, Oxford: Clarendon Press

Goldie, P. 2004, "Emotion, Reason and Virtue", in: P. Cruse and D. Evans, eds., Emotion, Evolution and Rationality, Oxford: Oxford University Press, pp. 249-268

GoldiE, P. 2007, "Seeing What Is the Kind Thing to Do: Perception and Emotion in Morality", dialectica 61, pp. \#\#\#

Goldman, A. 1995, Aesthetic Value, Bolder: Westview

Hopkins, R. 2000, "Beauty and Testimony", in: A. O'Hear, ed., Philosophy, the Good, the True and the Beautiful, Cambridge: Cambridge University Press, pp.

Hopkins, R. 2001, "Kant, Quasi-Realism, and the Autonomy of Aesthetic Judgement", European Journal of Philosophy 9, pp. 166-189

Hume, D. 1998, "Of the Standard of Taste", in: D. Hume, Selected Essays, Oxford: Oxford University Press

Kant, I. 1990, Kritik der Urteilskraft, Hamburg: Meiner; cf. also I. Kant 1987, Critique of Judgement, Indianapolis: Hackett Publishing Company

Levinson, J. 1995, "Pleasure and the Value of Works of Art", in: J. Levinson, The Pleasures of Aesthetics, Ithaca: Cornell University Press

Levinson, J. 2002, "Hume's Standard of Taste: The Real Problem", Journal of Aesthetics and Art Criticism 60, pp. 227-238

McDowell, J. 1983, "Aesthetic Value, Objectivity, and the Fabric of the World", in: E. Schaper, ed., Pleasure, Preference and Value, Cambridge: Cambridge University Press

McDowell, J. 1985, "Values and Secondary Qualities", in: T. Honderich, ed., Morality and Objectivity, London: Routledge

McDowell, J. 1987, "Projection and Truth in Ethics", in: J. McDowell, 1998, Mind, Value, and Reality, Cambridge (Mass.): Harvard University Press

McFarland, D. and Miller, A. 1998, "Response-Dependence without Reduction?", Australasian Journal of Philosophy 76, pp. 407-425

McNaughton, D. 1988, Moral Vision, Oxford: Blackwell

Morton, A. 2002, "Emotional Truth", Proceedings of the Aristotelian Society, suppl. 76, pp. 265-275

Peacocke, C. 1995, A Study of Concepts, Cambridge (Mass.): MIT Press 
Sibley, F. 1965, "Aesthetic and Nonaesthetic", Philosophical Review 74, pp. 135-159

Sмiтh, M. 1994, The Moral Problem, Oxford: Blackwell

DE SousA, R. 2002, "Emotional Truth", Proceedings of the Aristotelian Society, suppl. 76, pp. 247-263

DE Sousa, R. 2003, "Emotional Consistency", Manuscript

DE Sousa, R. 2007, "Truth, Authenticity, and Rationality", dialectica 61, pp. \#\#\#

Todd, C. 2004, "Quasi-Realism, Acquaintance, and the Normative Claims of Aesthetic Judgement", British Journal of Aesthetics 44, pp. 277-296

Wiggins, D. 1987a, "Truth as Predicated of Moral Judgements", in: D. Wiggins, Needs, Values, Truth, Oxford: Blackwell

Wiggins, D. 1987b, "A Sensible Subjectivism?", in: D. Wiggins, Needs, Values, Truth, Oxford: Blackwell

Williams, B. 1965, "Morality and the Emotions", in B. Williams, 1973, Problems of the Self, Cambridge: Cambridge University Press

Wollheim, R. 1980, "Art and Evaluation", in: R. Wollheim, Art and its Objects, Cambridge: Cambridge University Press

Wright, C. 1988, "Moral Values, Projection and Secondary Qualities", Proceedings of the Aristotelian Society, suppl. 112, pp. 1-26

Wright, C. 1992, Truth and Objectivity, Cambridge (Mass.): Harvard University Press

Zangwill, N. 2001, The Metaphysics of Beauty, Ithaca: Cornell University Press 